\title{
Research on the Route of Engineering Geological Informatization
}

\author{
Kun Wang ${ }^{1,2}$, Yong $\mathrm{Wu}^{2}$, Chengjie Yang ${ }^{3}$, Junqing Zhang ${ }^{4}$ \\ ${ }^{1}$ School of Earth Sciences and Technology, Hehai University, Nanjing, 210098, China \\ ${ }^{2}$.Powerchina Kunming Engineering Corporation, Kunming 650051, China \\ ${ }^{3 .}$ North China University of Water Resources, Zhengzhou 450046, China \\ ${ }^{4}$ College of Computer Science China University of Geosciences, Wuhan, 430074, China
}

\begin{abstract}
This paper expounds the important status and characteristics of Hydropower Engineering Geological Information (HEGI) in the "Digital Hydropower" by the knowledge system, further analysed its two critical parts: the modern engineering geological investigation technology and geographic information system, and analyses the specific contents and the combined methods, it paves the way for the work for realizing better hydropower engineering geological information.
\end{abstract}

Keywords-digital hydropower; informationization of water and electricity; geological information; engineering geology computer; geological GIS.

\section{INTRODUCTION}

Information level has been as an important symbol to measure a comprehensive strength of country and region in the new economic era, if which is low will affect not only the enterprise competitiveness but also the country's [1]. Since the $1990 \mathrm{~s}$, information technology with the core of computer has been rapid development, therefore, lead to global information revolution. As a micro main body of market economy of enterprises, the informatization plays a basic role in the national economy informatization [2]. With the rapid development of economy and IT technology in the past 20 years, construction projects have been putted forward higher requirements from the depth, breadth and accuracy for engineering, and set off a wave of a "design revolution" integrated with "digitalization, visualization and intellectualization" [3]. Meanwhile, with increasing Labor costs [4], gradually reducing of easily development of hydropower, the role of informatization in water survey and design enterprises appears more prominent. Engineering geological work is the basis and prerequisite of water resources and hydropower engineering and construction, due to geological work is a half quantitative and qualitative work so far, so need to constantly introduce new theory, new technology and new methods to promote the maturity and development of the industry. Information technology as a cross-sectional technology system brought new opportunity to the development and a series of technical support for almost all trades and professions [5]. From digital earth [6], digital land [7], digital city [8], digital basin [9] etc., informatization construction can be seen infiltration, influence and support for them in modern society for various industries. Since the $1980 \mathrm{~S}$, especially the introduction of GIS technology [10] and the development of 3S, 4S [11], 5S [12], "Multi-S" [13] and modern exploration techniques, greatly promote HEGI processing level, and accelerate the development of engineering survey technology. Meanwhile, with the increasing range of application in the field of water conservancy, application level also is gradually thorough, and the social economic benefit is obviously out of the show. Information should have an overall planning to guide the planning and implementation of each stage [14], and this paper is in this case to carry out the work.

\section{PROCESS OF HEGI}

Hydropower engineering geological investigation is to find out the conditions and problems of engineering geological, to predict geological processes and phenomena after the reservoirs may arise, provide geological basis for reservoir processing design. Hydropower engineering geological investigation content mainly includes using various geological tools and means to grasp the lithology, geological time, geological structure and bad geological phenomenon of the geological object, even though grasp interaction between natural geological body and the human engineering, analyze and predict possible or happened geological phenomena and take measures to deal with the corresponding geological problems. It is a process learning nature and change nature, the computerization, digitization and informatization is a human thinking expression and a systematic process of knowledge, in conformity with law knowledge system, many of the ideas and methods about knowledge system was referenced. Knowledge system can be divided into five parts such as knowledge acquisition, knowledge management, knowledge discovery, knowledge expression and knowledge application (as shown in figure 1). According the process of knowledge system, geological information process is divided into five information processes included acquiring original geological data, handing original geological data, managing result data, modeling and visual expression of the results, using visual means to make some application analyses [15]. 

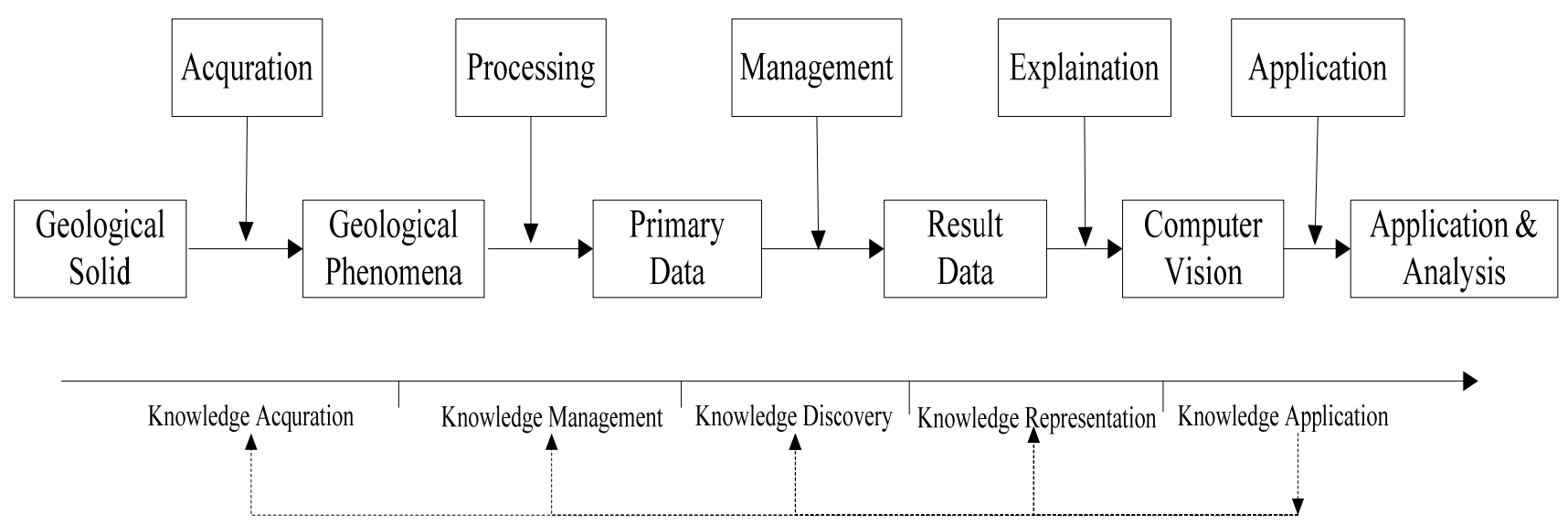

Figure 1. The work process of geological information

HEGI can be two key parts in the five steps:

1) Different acquisition methods and applications degree of Geological data directly affect the quality and quantity of geological data.

2) Software for information processing, management, interpretation and using ability directly affects the utilization degree and the function size of the geological data.

\section{METHOD OF HEGI}

Traditional hydropower engineering geological investigation included two processes of outdoor field investigation and indoor results compilation. Since the last century, high-tech means were brought into HEG professional continuously, indoor and outdoor business times have a huge changed, outdoor investigation time is relatively short, the process of exploration is quicker and more convenient, indoor maps are more beautiful, and application analysis is more convenient. On the whole, it shortens the exploration period, at the same time, improves the quality of the work. According to the information of two key parts, HEGI represent two main parts including applications of high-tech means and survey equipment in modern, and computer software of HEGI (see figure 2).

\section{A. Modern investigation techniques}

It is not reality to make a large scale areal or reservoir geology survey, explore, drilling and excavation that is traditional means of HEG's survey, therefore, more and more modern survey method has been applied to the investigation, such as RS, GPS, intelligent portable devices, internet of thing, geophysical exploration methods (including gravity and magnetic potential field exploration, seismic exploration, electromagnetic surveying, electrical prospecting, and geophysical well logging etc. [16]), these methods can improve quality and efficiency of geological data acquired.

1) RS: As one of the early of " $3 \mathrm{~S}$ ", it is an implements of, accessing regional and remote data quickly, regional geological phenomenon, geological structure distribution and water system as a whole, makes up for the deficiency of the traditional exploration and field geological survey, also provides a new way for geological survey work [17, $18]$. RS system is a kind of high performance information collection methods that study range includes the whole river basin and the influence area caused by dam project and the maximum range area, where the biggest scope geological body may affect dam. In accordance this, he river basin information related to dam safety is captured and analyzed. Through the analysis of remote sensing images, the three dimensional terrain DEM, soil erosion, humanities information, reservoir geology and basin based data can be got. Information obtained in a geographic information system for storage and analysis of water supply is used to assess electrical safety of engineering geology [19].

2)GPS: also as another part of $3 \mathrm{~S}$, is a new type of positioning-information acquisition technology and means by the form of survey point sources of static and quick positioning method that quickly obtain topography, geomorphology and geological object data [20]. It, for the traditional geological 3 big tools, is a new modern tools that geological survey, geological phenomenon associated with spatial information and attributes data. That solves the problem of positioning of remote sensing information, and realizes the remote sensing information directly access to the GIS database, and makes GPS also become a kind means of information sources and information update of geological survey. 


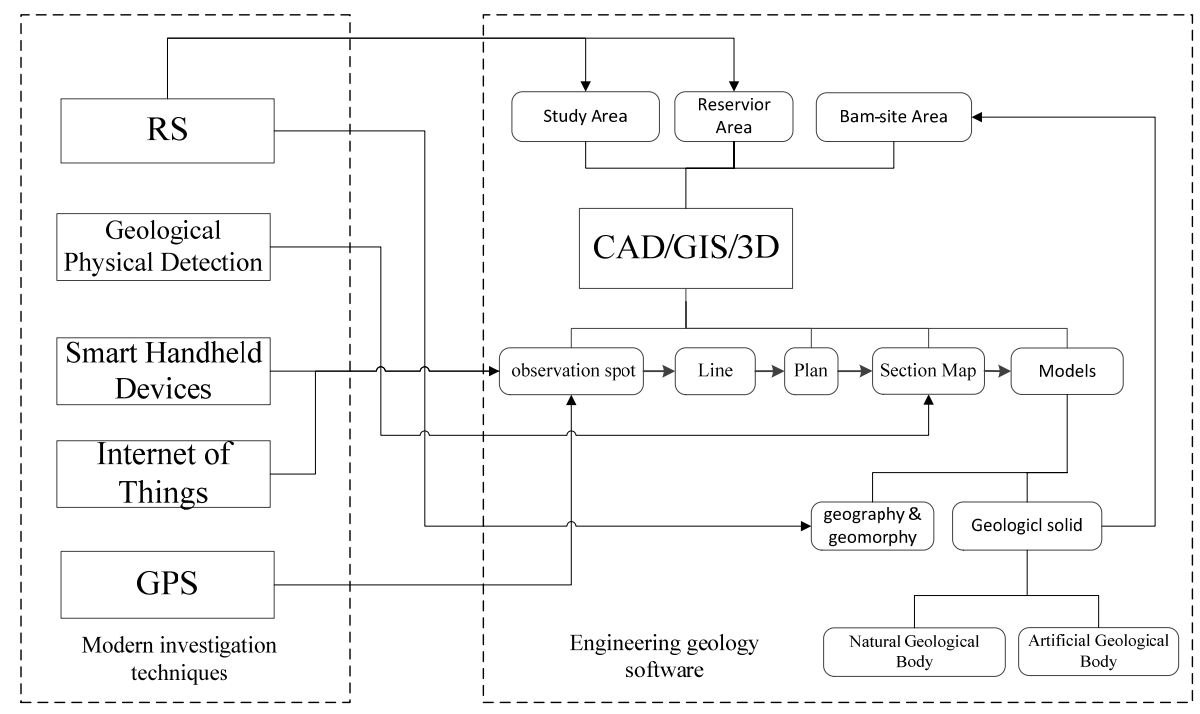

Figure 2. The work content and features of HEG

3) Intelligent Portable Equipment (IPE): It is mainly refers to the notebook, tablet computers, smart phones, hand-held terminals, etc., also some people call this embedded technology. The equipment has been able to provide data collected by GPS, audio, video, graphics of the field geological survey, etc. New five basic integrated geological tools (PDA, GPS, voice recorder, digital camera, digital video camera) with all of the features, these provides a material basis to achieve and collect digital of the field geological data [21]. It not only reduces intensity and of the field geological workers labor, improves the speed and precision of the field data measured, and realize the digitization and automation of the geological investigation from the source [22].

4) Internet of Things (IoT): It is a sensor network with some nodes that have some tiny smart sensors which have many capabilities of awareness, computing and communication [23]. The sensors monitor the stress, deformation and displacement of geological body, the position, velocity, temperature of groundwater, and access engineering geological and hydrogeological data, etc. It mainly used in two aspects including geological prospecting and geological disaster monitoring [24, 25].

5) Geological Physical Detection (GPD): Department related water resources

and hydropower engineering survey, from the early 1980 s to 90 s, gradually introduce advanced instruments to serve the project need such as the seismographs of signal enhancement type, the comprehensive logging instrument, electrical prospecting apparatus, scenograph, line instrument, geological radar and borehole color television system, etc., which make the geophysical prospecting instruments has been fully updated, and some of which are world level of new instruments at the time or up to now. It improved the precision of collection and analysis data and efficiency of the field work and promotes the development of geophysical technology and the level of HEGI.

\section{B. HEG software}

HEG software have very many, but can be divided into CAD drawing software (Fig. 3a), 3D modeling and simulation software and GIS software, which is both contact and some big differences. Although definition from the concept of GIS, the three may be included, but as a result of drawing software the fruits of success, people used to equate drawing software with GIS, think the GIS already very mature [26]. Though they have property management and spatial analysis function, but their ultimate goal is for drawings, that can only be called "Special GIS", is a 2D GIS (Fig. 3b). Some large scale of the three-dimensional modeling software for the earth's surface is 2.5D GIS (Fig. 3c), and geological 3D body modeling and simulation software system is called a true 3D GIS (Fig. 3d) [27]. Three kinds of software in hydropower engineering geological information processing plays a different role, although 2D GIS to 3D GIS development has a certain level, but not to say that the $3 \mathrm{D}$ can replace the $2 \mathrm{D}$, or $2.5 \mathrm{D}$ GIS, in a word, they play a different use in different aspects and time. There has a table to show the characteristics of similarities and differences as table 1: Compare of the advantage, disadvantage, and rang of application and common points about CAD and 2D, 2.5D and 3D GIS. 

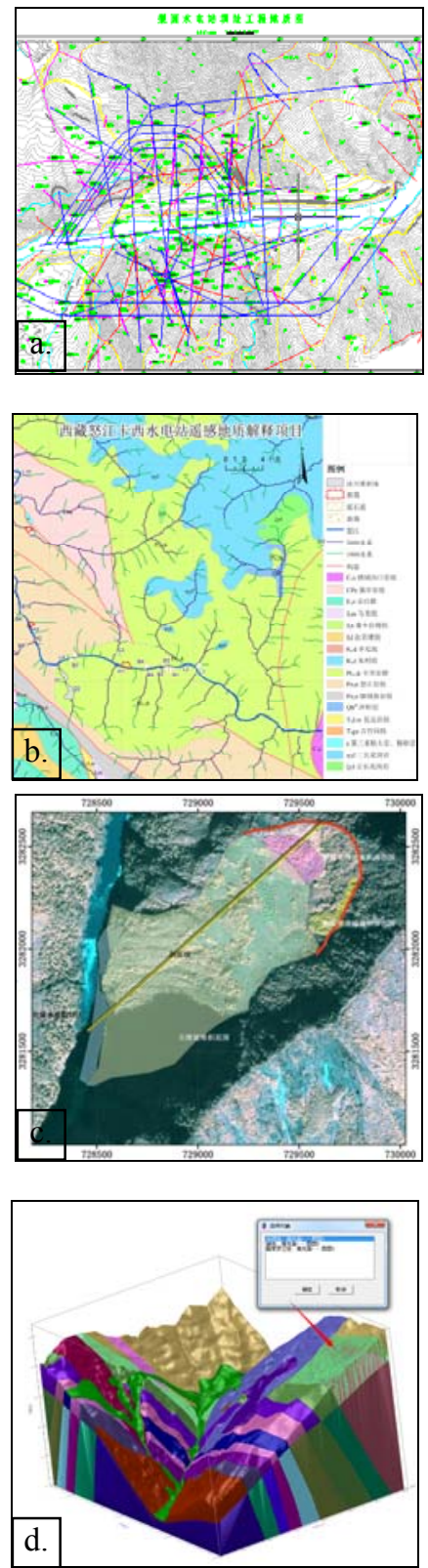

Figure 3. HEG software type: (a) 2D CAD and (b) GIS Map about power station. (b) 2.5D GIS Model of landslide. (c) 3D GIS Model of Gushui dam foundation.

1) 2D GIS can automatically make engineering geological maps such as geological plan, histogram, profile and contour map etc., handle graphics, images manage spatial data and attribute data, and do spatial analysis. CAD is mainly used in the real world does not exist object to carry on the design, and GIS is used to understand, analyze and manage resources and implementation for existing object modeling [28]. It is the main trend of engineering geological prospecting industry that GIS technology was applied to the engineering geological information management and graphics output in recent years. In general, hydropower engineering geological survey and mapping have coexistence of CAD and GIS [29]. The first application in the mold design CAD software has a large market share for convenient and favorite drawing method of geological workers, especially for building body that is homogeneous rules such as slope treatment, dam foundation, workshop and diversion tunnel, so CAD become the best choice. Although it don't has data interface conversion problems by engineering geology with $\mathrm{CAD}$ as same the construction department, but have the data property management and cause inherent flaws of no space analysis. Finally the use of CAD and GIS software drawing will exist in drawing at the same time [30]. In a sense, the GIS can replace CAD software, but not the opposite.

2) $2.5 \mathrm{D}$ GIS is a kind of planar $3 \mathrm{D}$ expression, and i applicable to a wide range of remote sensing images and add digital elevation formed on the basis of 3D surface, which mainly uses the LOD of huge amounts of data capacity such as scheduling, load and browse [31]. It can be used to handle different resolution and hierarchical data for a wide range of geological research scope, and helpful to identify the distribution of regional geological structure, lithology and shape of the scope of geological phenomena, physical expression, etc.

3) 3D GIS is one of the most important aspects and development direction of computer technology application in the geology [32], and abstract a large number of geological data and analysis and judgment result of geological personnel into geological visualization model, complex spatial relationships into visualize scene, and show the model from a different perspective by the rotation operation, where image is very intuitive, it make full use of computer management and analysis method, in which data are inputted and calculated by index scale, models are measured, and output results are integrated as a data flow, the fully digital information processing is realized. Finally, rapid, effective, accurate and modern tools are provided for water resources and hydropower engineering (WRHE) [33]. 
TABLE I. COMPARE OF THE ADVANTAGE, DISADVANTAGE, RANG OF APPLICATION AND COMMON POINTS ABOUT CAD AND 2D, 2.5D AND 3D GIS.

\begin{tabular}{|c|c|c|c|c|}
\hline Items & Advantage & Disadvantage & Range of Application & Common Points \\
\hline$C A D$ & $\begin{array}{l}\text { Good drawing, operation habit and } \\
\text { Size expressing }\end{array}$ & $\begin{array}{l}\text { No attribute management 、 Spatial } \\
\text { analysis function and Spatial } \\
\text { analysis function, Elevation and 3D } \\
\text { terrain }\end{array}$ & $\begin{array}{l}\text { Disaster prevention and control of } \\
\text { project design, layout of } \\
\text { prospecting and graphic drawing } \\
\text { quickly. }\end{array}$ & \multirow{4}{*}{$\begin{array}{l}2 \mathrm{D} \text { drawing and } \\
\text { space expression, } \\
\text { mapping of plane } \\
\text { and section. }\end{array}$} \\
\hline $2 D G I S$ & $\begin{array}{l}\text { Strict management relations of } \\
\text { space and property, layer associated } \\
\text { with illustrations, many } \\
\text { professional tools of spatial analysis } \\
\text { and mapping }\end{array}$ & $\begin{array}{l}\text { Discommodious control and design } \\
\text { on exploration layout and slope, less } \\
\text { resource style, no elevation and } \\
\text { three-dimensional concept and size } \\
\text { express }\end{array}$ & $\begin{array}{l}\text { Spatial and attribute management } \\
\text { integration, spatial analysis and } \\
\text { the coordinate transformation, and } \\
\text { craphic drawing. }\end{array}$ & \\
\hline 2.5D GIS & $\begin{array}{l}\text { Large surface lifelike } 3 \mathrm{D} \\
\text { expression, loading generalized } \\
\text { model, projection lines, flood } \\
\text { analysis is convenient. }\end{array}$ & $\begin{array}{l}\text { Less and monotonous space analysis } \\
\text { function, simple and week 3D } \\
\text { model, modeling, less profile } \\
\text { information and no size express }\end{array}$ & $\begin{array}{l}\text { Large terrain expression, regional } \\
\text { geomorphic and tectonic analysis } \\
\text { and results show and remote } \\
\text { sensing }\end{array}$ & \\
\hline $3 D$ GIS & $\begin{array}{l}\text { Arbitrarily cutting to get plane and } \\
\text { section, easy analysis, strong } \\
\text { modeling and spatial expression } \\
\text { capability and building complex } 3 \mathrm{~d} \\
\text { model. }\end{array}$ & $\begin{array}{l}\text { weak ability for drawing, symbolic } \\
\text { express and large surface data } \\
\text { scheduling, No size express }\end{array}$ & $\begin{array}{l}\text { Body modeling of Dam } \\
\begin{array}{l}\text { foundation, yard, disaster, } \\
\text { complex } \\
\text { geological }\end{array} \text { 3D expression and } \\
\text { analysis. }\end{array}$ & \\
\hline
\end{tabular}

\section{CONCLUSION}

The paper put forward a new acquisition mode with new prospecting technologies such as GPS, RS, IoT, IPE and GPT, which is fast to access and update the reservoir and dam foundation data, with GIS as the storage management, and the analysis of basin reservoir space information and data platform. Modern science and technology means in HEG has transcended the category of traditional "3S", survey method determines the source of the geological data, and GIS is the core of the expression, analysis, using of the final results. When China's HEGI is being in a stage of rapid development, reviewing and rethinking the current informatization technology and application methods of WRHE, and vigorously promoting the development of all kinds of information method and its comprehensive application in the paper, it is help of development from "qualitative analysis" to "quantitative calculation" of HEG. Modern investigation techniques and geological information software and the traditional means of together to speed up the process of "Digital Hydropower", to speed up the development of water resources and hydropower engineering in China is of great significance.

\section{ACKNOWLEDGEMENTS}

The research work was supported by Innovation Foundation of Yunnan Province under project grant No. 2010CI056, science and technology project of Corporation under contract No. GW-KJ-2011-10, science and technology project of China power Construction Corporation under contract No. AQ2013-1 and National
Natural Science Foundation of China under project grant No. 41201382 Finally, we are indebted to the anonymous reviewers for helpful suggestions that improved the quality of this paper.

\section{REFERENCES}

[1] Cui Liu, Li Zheng. "Disscus on the Infromation of Mineral Enterprise, " in Coal Minning Technology, 2005,10(4): 8-10

[2] Wang Yukai. Informatization Level as the Important Symbol of National Innovation Ability, in Study of Socialism with Chinese Characteristics , 2008(01):111-111

[3] Zhong Denhua, Song Yang, Song Yangang, Den Liangsheng. "Research on Building 3D Visualization Modeling Technique for Large Water Conservancy and Hydropower Engineering," in Water Resources and Hydropower Engineering, 2003(2):62-65

[4] Li Zhiye. Labor costs increase $47 \%$ in the last three years. http://shszx.eastday.com/node2/node4810/node4851/qxzx/u1ai686 40.html

[5] Liu Junqi, Wu Chonglong, Hang Changqing, Liu Gang, Mao xiaoping, "Main Method of Water Resources and Hydropower Engineering Geological Survey and Its Development," in Yangtze River. 2007, 38(8): 120- 123

[6] Core, A. The digital Earth: Understanding our piance in the 21 st century. The Australian Surveyor, 1998, 43(2) : 89 91.

[7] Yuan Yanbing, Liu Gang, Han zhijun, Wang Xingqing,. "Digital land in Status of Digital Earth and Its Model discusse," in Geological Science and Technology Information, 1999, 18(3):91 93

[8] Li Deren, Zhu Qing "CyberCity: Concept, Technique Support and Typical Applications," in Geomatics World, 2000, (3):283-288

[9] Zhang Yongchuan, Wangchen. "Diaital Basin-An important regional level of digital earth," in Water Resources and Power, 2001,19(3):1-3 
[10] Ding Yuncheng. "Application of GIS in Water Conservancy and Hydropower Project Construction and Management," in Coastal Enterprises with Science and Technology. 2009,114(11):157-159

[11] Wu Zhongyu, Yu Long. "'4S' integration technology in the application of dam safety," in Water Resources and Power. 2001,19(3):16-22

[12] Du Daosheng. "Water Resources and Power" M. Wuhan University of Surveying and Mapping Science and Technology press, 1995

[13] Wang Xingqing, Liu Gang. "Development of Geotechnical Engineering Investigation of Point Source Program Information System," Seminar on Digital Surveying and Mapping and GIS Application. 2000: 73 79.

[14] Wang Jiye. "Information Technology Roadmap" from the Chief-e in ELECTRIC POWER IT,2009,7(11)

[15] Li Rongwei, Hou Enke. "Main Method of Water Resources and Hydropower Engineering Geological Survey and Its Development," in Sichuan Water Power, 2007,26(6): 89-92

[16] Yang jing Zhong. Application of Remote Sensing Technology in the Engineering Eeological Location Work. Remote sensing of land and resources, 2007,74(4):90-94

[17] Peng Tubiao, Hydropower Engineering Geology Manual (1rst editon). China's Hydropower Press. 2011

[18] Wu Yong, Wang Kun, Liu Jian. "3S technology Application in hydropower Engineering Geological Disaster survey, " in 2012 Academic Essays on Water Conservancy Power Geophysical Technology Information Network of China's Academy of Engineering Geology and Exploration, 2012:112-116

[19] Wu Yong. Facing Complex Geological Constraints of Modeling and Dynamic Simulation of Complex Model Research, China university of Geosciences (wuhan). 2011

[20] Gong Zhengjun. "Application of GPS Technology in Water Resources and Hydropower Engineering Survey Research," in Motivation and Electrical Engineering,2009,2:149

[21] Li Yuxing, Bai Wangcheng, Qing Min, Wang Qun. “Application based on Embedded Technology of Internet of Things in the Regional Geological Survey," in Engineering Research Interdisciplinary Field of Engineering, 2013,37(2):358-362

[22] Guo Fusheng, Wu zhichun,Xie Caifu, Liu Lingqing, Jiang Yongbiao. "Some Opinions for Improvement of Digital Geological
Mapping System and Practical Skills," in Geology of China, 2012, 39 (1): 252-259

[23] Wu Lixing, Wang Yunjia, Ding Enjie, Zhu Wangxi, Zhang Rexin, Zhan Sen. "Thirdly study on digital mine: serve for mine safety and intellimine with support form IoT, " in Jouna of China Coal Society, 2012,37(3): 357-363

[24] Cheng Mingxuan. "Research Based on Geological Information Field of IoT technology." in Electronic Technology and Software Engineering, 2014,4: 46-48

[25] Xu Yongqing, Ma Juan, “Geological Disaster Dynamic Monitoring and Early Warning System and Its Architecture Based on IoT, " in Chinese Journal of Prevention and Control of Geologic Disasters, 2013,9,24(3): 90-93

[26] MAGUIRE D J. Improve CAD-GIS Interoperability [DB/OL]. http://www.geoplace.com/gw/1998/0698/698mrtch.asp.

[27] Zhu Qing. "Technology Progress of Three Dimesional GIS," in Progress of International Photogrammetry and Remote Sensing. 2011, 2: 25-27

[28] NEWELL R G,SANCHA T L.The Difference between CAD and GIS[DB/OL].

http://emea.smallworld.co.uk/support/techpaper/tp2.html.

[29] Wang Liyuan, Cheng Chujian. "Highway Tunnel and Surrounding Rock Mass 3D visualization system Based on CAD/GIS technology, " in Highway Traffic Science and Technology, 2012,29(4)

[30] Zhang Xueshong, Zhang Yuan, Den Min. "Method of Orgnizing GIS Data in AutoCAD Enviroment," in Bulletin of Surveying and Mapping, 2003, 11:45-48

[31] Zhu Qing, "3D GIS and Its Application in Intelligent City," in Journal of Earth Science Information, 2014,16(2)

[32] Wang Ruiyao, "the Analysis of Sistutation and Development of 3D Viasulization on Water Resource and Hydropower Engineering, " in Shanxi Arcthitecture, 2014,40(2):231-232

[33] Zhao Pan, Tian Yiping, Liu Junqi, Liu Zhifeng, "3D geological Modeling and Its Application in Water Conservancy and Hydropower Engineering, " in Chinese Journal of Engineering Geophysics, 2007,4(5):520-524 